Portland State University

PDXScholar

\title{
Fifth Year Persisters: High School, College, and Early Career Outcomes For Persisting Non-Graduates
}

\author{
Mathew C. Uretsky \\ Portland State University, muretsky@pdx.edu \\ Angela K. Henneberger \\ University of Maryland, Baltimore
}

Follow this and additional works at: https://pdxscholar.library.pdx.edu/socwork_fac

Part of the Child Psychology Commons, and the Social Work Commons Let us know how access to this document benefits you.

\section{Citation Details}

Mathew C. Uretsky, Angela K. Henneberger, Fifth year persisters: High school, college, and early career outcomes for persisting non-graduates, Children and Youth Services Review, Volume 115, 2020, 105058, https://doi.org/10.1016/j.childyouth.2020.105058.

This Post-Print is brought to you for free and open access. It has been accepted for inclusion in School of Social Work Faculty Publications and Presentations by an authorized administrator of PDXScholar. Please contact us if we can make this document more accessible: pdxscholar@pdx.edu. 
Fifth Year Persisters: High School, College, and Early Career Outcomes for Persisting NonGraduates

\author{
Mathew C. Uretsky ${ }^{1,3}$ \& Angela K. Henneberger ${ }^{2,3}$ \\ ${ }^{1}$ Portland State University \\ ${ }^{2}$ University of Maryland School of Social Work \\ ${ }^{3}$ Maryland Longitudinal Data System Center
}

Suggested Citation:

Uretsky, M.C., \& Henneberger, A.K. (2020). Fifth year persisters: High School, college, and early career outcomes for persisting non-graduates. Children and Youth Services Review.

\title{
Acknowledgements
}

This research was made possible with data, technical, and research support provided by the Maryland Longitudinal Data System Center. The views and opinions expressed are those of the authors and do not reflect the opinion of the State of Maryland, the MLDS Center, the MLDS Governing Board, or its partner agencies. 


\begin{abstract}
There is limited extant knowledge regarding academic and workforce experiences of students who remain engaged in high school, but do not graduate in the traditional four years. The current study used Multilevel modeling and descriptive statistics with statewide linked longitudinal administrative data $(\mathrm{N}=2,917)$ to (1) examine the student- and school-level factors related to earning a diploma during the fifth year of high school and (2) describe proximate academic and career outcomes for non-graduates and fifth year graduates. Multiple student-level factors were associated with increased likelihood of earning a diploma in the fifth year (e.g. special education eligibility, passing exit exams, higher attendance). Returning dropouts were less likely than persisters to earn a diploma in year five. In addition, the type and composition of the school a student attended affected the likelihood that a student would earn a diploma in year five. We also report population-level rates of participation in the workforce and postsecondary enrollment for fifth-year graduates and non-graduates. Fifth-year graduates outperformed non-graduates in both categories. Our findings provide insight into near term outcomes for students in a fifth-year of high school and suggest key factors that can be used for early identification and targeting services towards this under-researched and under-served population.
\end{abstract}




\section{Introduction}

As youth depart adolescence and begin their journey towards adulthood, their educational attainment is closely linked to key life outcomes such as mental health, physical well-being, and participation in the workforce (Blackwell, Lucas \& Clarke, 2014; Kena et al., 2014; Rouse, 2007). For example, young adults who leave school without a diploma are more likely than high school (HS) graduates to experience unemployment, participate in government assistance programs, or be arrested for larceny, assault, and drug offenses (Maynard et al., 2015). Many researchers and practitioners have come to view dropout as a major public health issue requiring immediate and intensive intervention and prevention programming (Dynarski, Clarke, Cobb, Finn, Rumberger, \& Smink, 2008; Freudenberg \& Ruglis, 2007). Accordingly, there have been a myriad of efforts, focused on preventing students from leaving school early and reengaging students who have dropped out (Dynarski et al., 2008; Freeman \& Simonsen, 2015). In contrast, we know very little about the conditions or correlates of success among students returning for a fifth-year of high school. Consequently, we know even less about the subsequent outcomes for these students in college and the early labor market.

The absence of inquiry into the fifth-year experiences of non-graduates may be due in part to the common practice of researchers defining HS attainment as a dichotomous outcome, with students either dropping out or graduating. Recently scholars have begun to identify and examine a second, often overlooked, group of non-graduates - referred to here as persisters (Hill \& Mirakhur, 2018; Uretsky, Henneberger, \& Woolley, 2016; Uretsky, 2019). Persisters are students who do not drop out or earn a diploma after four years of high school (Uretsky, 2019). Unlike dropouts, persisters remain behaviorally engaged in school making them a prime target for intervention. Nevertheless, persisters have received minimal attention in the research 
literature. Consequently, we know very little about the student- and school-level predictors of success in the fifth year of HS. To fill this gap, the current study used linked administrative academic and workforce data to (1) describe the population of persisting non-graduates in Maryland; (2) examine the student and school-level predictors of fifth-year graduation; and (3) describe the postsecondary and early career outcomes for non-graduates and fifth-year graduates.

\subsection{Background}

Although the potential benefits of increasing the HS graduation rate in the U.S. have been part of the national conversation for more than half a century, the primary focus has been on four-year graduation and dropout prevention (Rumberger, 2011; Zaff et al., 2016). Although dropout rates have reached historic lows, and four-year graduation rates have reached historic highs, there remains a large group of students who persist past the fourth year in hopes of earning a diploma (Hill \& Mirakhur, 2018; Uretsky, 2019; Uretsky, Henneberger, \& Woolley, 2016). In other words, not all non-graduates are dropouts. The complex heterogeneity among nongraduates has been illustrated by recent population studies that have identified between 8 and $22 \%$ of the student population as persisters and about $8 \%$ as dropouts (Hill \& Mirakhur, 2018; Uretsky, 2019; Uretsky, Henneberger, \& Woolley, 2016). The findings from these studies suggest that the current status quo_ of focusing research, intervention, and prevention efforts primarily on dropout — excludes the bulk of HS students who do not earn a diploma in four years. In an explicit acknowledgement of this dynamic, at least 35 states are currently, or have imminent plans to begin, reporting extended graduation rates that capture fifth and sometime sixth-year graduates in their counts (Rumberger \& Sublett, 2017).

\subsection{Graduates, persisters, and dropouts}


An important characteristic of both persisting and dropping out is that they are actions, not outcomes. Figure 1 presents a systems diagram illustrating possible within-system academic pathways and outcomes during Years 4 and 5. If a student formally withdraws from school before the end of Year 4 they have dropped out. If they do not formally withdraw from school or earn a high school diploma by the end of Year 4 they are a persister. Both dropouts and persisters could subsequently enroll in a fifth-year of HS, as a persisting non-graduate, with the potential of going on to earn a HS diploma, dropping out, or persisting through their fifth-year without earning a diploma. Of course, there are multiple alternate pathways for non-graduates. For example, students may also go on to join the workforce, enroll in a community college, complete a General Educational Development (GED) certificate, or receive an alternative education degree many years after leaving school (Bowers, 2010; Pallas, 2003). However, research has consistently demonstrated that HS graduates have preferable life outcomes to both non-graduates and alternative certificate holders across multiple domains including health, income, and incarceration (Blackwell et al., 2014; Kena et al., 2014; Rouse, 2007). 


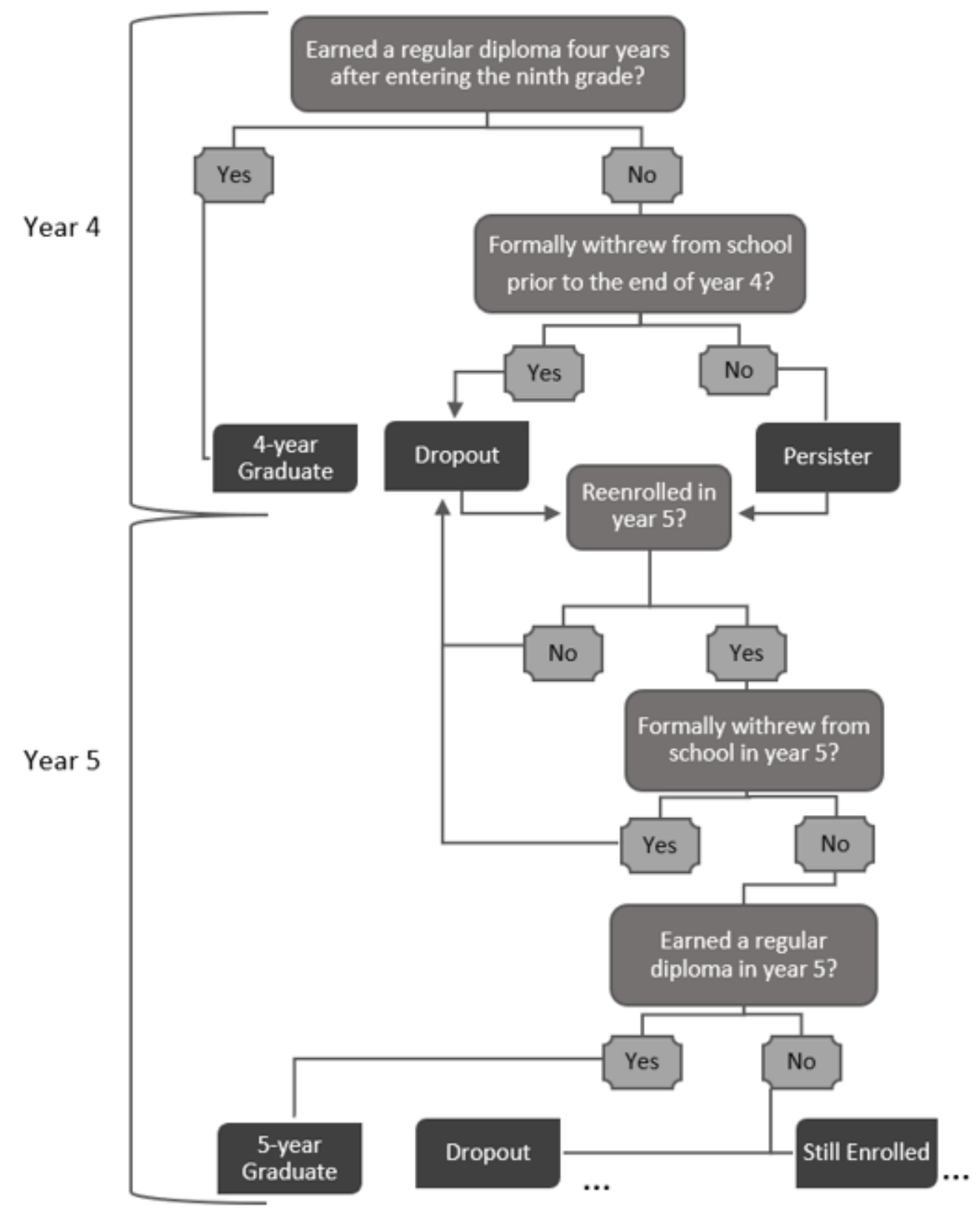

Figure 1. Systems diagram illustrating possible within-system academic pathways and outcomes during Years 4 and 5

\subsection{Student- and School-level Correlates of High School Graduation}

In our review of the literature we were unable to identify any peer-reviewed research examining fifth-year graduation. There is however a large body of literature detailing the student- and school-level correlates of on-time (fourth-year) graduation and dropout, which may 
be instructive when considering fifth-year graduation. Building upon Bronfenbrenner's (2005) ecological systems framework, Rumberger's (2011) Conceptual Model of High School Performance details individual characteristics and school-level characteristics that contribute to student outcomes, including HS graduation. This is in many ways a departure from past work considering HS completion which attended principally to student-level behaviors and characteristics. Individual characteristics include academic performance, behaviors, attitudes, and student background. School-level characteristics include differences in composition, structure, resources, and practices. Rumberger also highlights the importance of the family and community contexts, which are not examined here.

Student-level factors. Disparities in academic performance and attainment by race, ethnicity, and gender have driven much of the academic research over the last half century (De Witte, Cabus, Thyssen, Groot, \& van den Brink, 2013; Rumberger \& Lim, 2008). The results of this research have been mixed. Much of the uncontrolled (e.g. bivariate, single-level models) have demonstrated sustained disparities in academic performance (e.g. grades, standardized tests) and attainment (e.g. credit accrual, graduation; De Witte et al., 2013; Rumberger \& Lim, 2008). In studies that controlled for school-level factors and the economic background and/or history of homelessness, researchers have described statistically or clinically insignificant effects for gender and race (De Witte et al., 2013; Rumberger \& Lim, 2008; Henneberger et al., 2020). The same phenomenon has been described when considering the academic effects of ethnicity (De Witte et al., 2013) and special education eligibility (Zablocki \& Krezmien, 2013). Others have suggested that it is imprudent to analyze race or ethnicity without also considering the potential confounding effects of English proficiency or immigration (De Witte et al., 2013).

Rumberger's (2011) conceptual model highlighted student academic engagement and achievement as critical antecedents of dropout. Academic engagement is frequently measured 
using student attendance, likely due to availability in administrative data systems. The relationship between attendance and on-time graduation and dropout is well established and attendance is considered among the most efficient predictors of high school completion (Bowers, Sprott, \& Taff, 2013; Carl, Richardson, Cheng, Kim \& Meyer, 2013; Mac Iver \& Messel, 2012). The sensitivity and specificity of the relationship, however is heavily dependent on the operationalization of attendance (Bowers et al., 2013). Academic achievement is typically measured using academic performance measures (e.g. grades, test scores), educational persistence measures (e.g. prior dropout, mobility), and attainment measures (e.g. credit accumulation, grade promotion). Both prior dropout (Berliner, Barrat, Fong, \& Shirk, 2008) and mobility (Benenson, Markovits, Thompson, \& Wrangham, 2011; Dupere, Archambault, Leventhal, Dion, \& Anderson, 2015; Fantuzzo, LeBoeuf, Chen, Rouse, \& Culhane, 2012) are related to lower odds of on-time graduation, but timing and context may impact the strength or even the direction of the relationship (Berliner et al., 2008). On-time promotion and credit accumulation are considered to be effective indicators of on-time graduation (Allensworth \& Easton, 2007; Bowers et al. 2013). However, the two cannot be easily disentangled in high school because grade promotion is a function of credit accumulation, and social promotion is only permitted for students working towards certain special education specific credentials (e.g. certificate of completion).

School-level factors. Rumberger argued that differences in school composition, structure, resources, and practices are important for understanding student academic performance. The model defines composition as school-level concentrations of student characteristics-- such as non-promotion (Rumberger \& Thomas, 2000; Subedi \& Howard, 2013), student mobility (Rumberger \& Palardy, 2004), low income (Henneberger, Rose, Mushonga, Nam, \& Preston, 2020; Rumberger \& Thomas, 2000), and minority students (Sander, 2001). Higher 
concentrations of such characteristics have been associated with increases in dropout and lower graduation rates. Structure is usually defined via school type (e.g. Charter, Alternative, Private). Although the literature is mixed, charter and private schools tend to have higher graduation rates (Booker, Sass, Gill, \& Zimmer, 2011; Rumberger, 2011). Rumberger also suggested the importance of considering school resources and practices when examining high school graduation, however such information is generally not included in administrative data and thus not reviewed here.

\subsection{Fifth Year Reenrollment and High School Graduation}

There are three prior studies that, to a limited extent, describe reenrollment patterns for persisters or prior dropouts. Two studies, conducted in Baltimore and New York city, found that two thirds of persisting non-graduates reenrolled for a fifth year of HS (Hill \& Mirakhur, 2018; Uretsky, 2019). Another study conducted in San Bernardino, CA reported that one third of prior dropouts reenrolled in school at some point (Berliner, Barrat, Fong, and Shirk, 2008). The findings suggest that the timing of dropout was critical—with almost half of first- or second-year dropouts reenrolling, compared to less than $10 \%$ of third- or fourth-year dropouts. Across the studies, between one-fifth and one-half of students who did reenroll, earned a diploma within two years of their anticipated date (Berliner et al., 2008; Hill \& Mirakhur, 2018; Uretsky, 2019).

The prior research examining fourth- and fifth-year high school graduation and reenrollment is likely limited by selection bias, whereby the most highly motivated, highly resourced, and highest achieving students may be more likely to reenroll or persist to graduation. Prior studies examining dropout and on-time graduation have documented demographic and socioeconomic differences favoring students from more privileged backgrounds (De Witte et al., 2013). As such, it is plausible that both the likelihood of enrollment and graduation in the fifth 
year, and the improved life outcomes observed among high school graduates could be correlates of racism, heterosexism, and poverty, rather than the direct effects of earning a high school diploma.

Persisters as a group are at least equal in size to dropouts, and far outnumber dropouts in urban and low-income areas such as Baltimore or New York City, where non-graduation is relatively more common (Hill \& Mirakhur, 2018; Uretsky, 2019). Still, persisters have received limited attention in the research literature. As a consequence, we know very little about the short and long-term academic outcomes of persisting non-graduates, including secondary, postsecondary, and early labor market outcomes. These gaps in the literature are likely due to several data constraints, including the scarcity of linked cross-sector (e.g., K-12, postsecondary, career) administrative data. Understanding the mechanisms that support eventual graduation for students who do not earn a HS diploma in four years is central to developing and targeting interventions that could have a cascading effect on multiple key life outcomes, including health, socioeconomic, and behavioral outcomes.

\subsection{Research Questions}

The present study examines the student- and school-level correlates of earning a diploma in the fifth year of high school among a cohort of first-time freshmen in Maryland Public Schools. Additionally, we describe proximal life outcomes including college and early labor market participation. Specifically, we used statewide linked longitudinal administrative data to address the following research questions:

Research Question 1. Do student- and school-level factors, common to the dropout literature, contribute to the odds of earning a diploma during a fifth-year of high school? 
Research Question 2. What are the proximal college and early labor market experiences of persisting non-graduates who do, and do not, earn a diploma in the fifth year?

\section{Methods}

The current study draws on seven years of de-identified linked administrative education and workforce data from Maryland, a Mid-Atlantic state enrolling nearly 900,000 k-12 students in 2019 with and attendance rate over 90\% and a graduation rate nearing 87\% (Maryland State Department of Education, 2020). The data was provided by the Maryland Longitudinal Data System (MLDS) Center, an independent agency and is responsible for linking and housing longitudinal data from the Maryland State Department of Education, the Maryland Higher Education Commission, and the Maryland Department of Labor. Out-of-state college enrollments are provided for Maryland public $12^{\text {th }}$ grade students through the National Student Clearinghouse. At the time that the data for the current study was accessed, the MLDS included de-identified individual level data for all students attending public schools in Maryland beginning with the 2007-08 school year (SY) and ending with SY 2015-16.

\subsection{Data Protections and IRB}

The MLDS Center requires a federal background check and security training prior to accessing data. To protect confidentiality, all findings were aggregated to the population level. In order to ensure compliance with the MLDS Center reporting standards, all percentages were rounded to the nearest whole number and any categories that included fewer than 10 students were excluded from the analyses and reported findings (NCES, 2010). The University of Maryland and Portland State University Institutional Review Boards approved the study.

\subsection{Cohort Selection}


The cohort for the current study was constructed by identifying students who enrolled in a Maryland public HS as a first-time freshman for a period of 90 days or more during school year (SY) 2009-10 (Year 1) and attended a Maryland public HS in SY 2012-13 (Year 4) or SY 201314 (Year 5). A consort diagram detailing sample selection is provided in Figure 2. Students who formally withdrew or transferred out of the Maryland public schools prior to Year 4 and did not re-enroll during Year 4 or Year 5 were not included in the study. Of the 52,802 students from the Year 1 cohort who enrolled in a Maryland public HS in Year 4, 91\% $(n=48,061)$ graduated in Year 4. Students who attended schools that exclusively enrolled special education students $(n=49)$ or were seeking a certificate of completion $(n=132)$ were excluded from the present study. A total of 4,560 students met the inclusion criteria. Of those students $22 \%(n=995)$ dropped out during Year 4 and $78 \%$ were persisters $(n=3,565)$. A total of 2,793 students who were enrolled in Year 4 also enrolled in Year 5 and had no missing data. An additional 124 students who had dropped out before Year 4 enrolled in Year 5 resulting in a final sample of 2,917 students enrolled in 216 public HSs across 24 districts. 


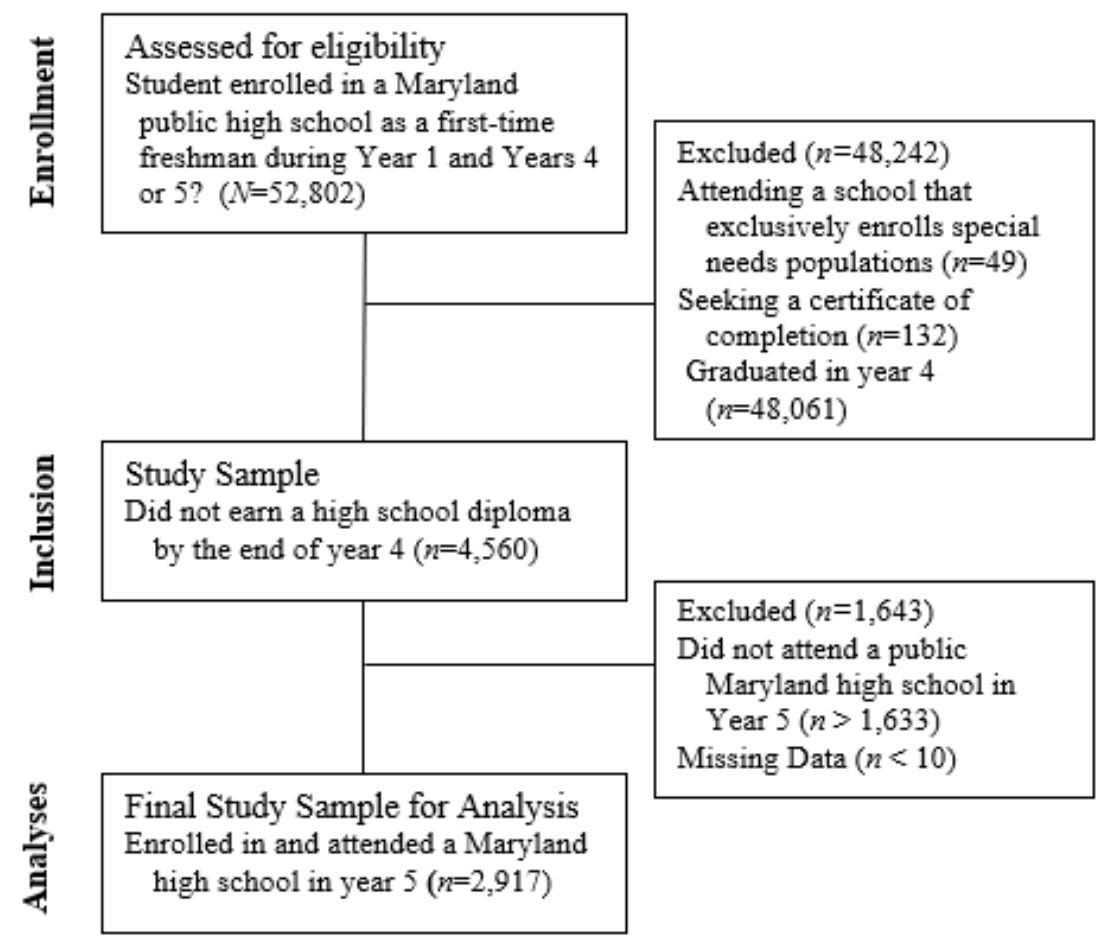

Figure 2. Consort Diagram for Selection of Study Sample.

Note. This flowchart is an adaptation of the flowchart offered by the CONSORT Group (Altman et al., 2001; Moher, Schulz, \& Altman, 2001). Journals publishing the original CONSORT flowchart have waived copyright protection

A summary of student characteristics for the Year 5 (study) cohort along with comparisons of student-level characteristics by fifth-year graduation status are presented in Table 1. Several student characteristics were significantly related to fifth-year graduation. Male students (51\%) graduated at a higher rate than female students $\left(46 \% ; \chi^{2}=5.274, p=.019\right)$. White $(55 \%)$ and Other race students $(55 \%)$ graduated at higher rates than Black students $\left(46 \% ; \chi^{2}=19.816, p<\right.$ .0001). The fifth-year graduation rate was higher for English language learners (57\% vs. 49\%; $\chi^{2}$ $=4.197, p=.041)$ and students who worked during their fifth year (57 vs. $41 \% ; \chi^{2}=69.447, p$ $<.0001)$. Students who were eligible for the free and reduced meals program (FARMs) graduated at a lower rate $(46 \%)$ than non-FARMs eligible students $\left(61 \% ; \chi^{2}=45.693, p<.0001\right)$. 
There was no significant relationship between being Hispanic $(p=.099)$, receiving special education services $(p=.908)$, experiencing homelessness $(p=.104)$, or experiencing mobility $(p$ $=.102$ ) and earning a diploma in the fifth year.

Student academic characteristics were also significantly related to fifth-year graduation. Students who passed their English HSA (66\% vs. $\left.41 \% ; \chi^{2}=169.990, p<.0001\right)$ or math HSA $\left(62 \%\right.$ vs. $\left.41 \% ; \chi^{2}=127.231, p<.0001\right)$ by the beginning of Year 5 had a higher fifth-year graduation rate. The fifth-year graduation rate for students who had dropped out of school at least once in years one through four was lower than students who had never dropped out (33\% vs. $\left.52 \% ; \chi^{2}=46.520, p<.0001\right)$. In addition, fifth-year graduates attended about 10 more weeks of school in their fifth year than fifth-year non-graduates $(t=-32.66, p<.0001)$. This means that the average fifth-year graduate attended about $84 \%$ of days in their fifth year; whereas the average non-graduate attended about $55 \%$ of days in their fifth year. For reference, the Maryland State threshold for chronic truancy is an attendance rate below $80 \%$.

There were also significant differences in fifth-year graduation depending on the type of school the students attended $\left(\chi^{2}=218.141, p<.0001\right)$. Fifty-nine percent of students who attended a Traditional HS graduated in the fifth year, whereas $23 \%$ attending a Combined HS, 44\% attending a Voc-tec HS, 32\% attending an Alternative HS, and 28\% attending a Charter HS graduated in the fifth year. 
Table 1

Results of the Bivariate Comparisons of Student Characteristics by Fifth-year Graduation Outcomes (N=2,946)

\begin{tabular}{|c|c|c|c|c|c|c|}
\hline & & \multicolumn{3}{|c|}{$\begin{array}{c}\text { Fifth Year } \\
\text { Graduate }\end{array}$} & \multirow[b]{3}{*}{$\chi^{2}$} & \multirow[b]{3}{*}{$p$} \\
\hline & & Total & Yes & No & & \\
\hline & & $N$ & $\%$ & $\%$ & & \\
\hline Total & & 2,917 & 49 & 51 & & \\
\hline Gender & Male & 1,882 & 51 & 49 & 5.474 & .019 \\
\hline & Female & 1,035 & 46 & 54 & & \\
\hline Race & White & 568 & 55 & 45 & 19.816 & $<.0001$ \\
\hline & Black & 1,909 & 46 & 54 & & \\
\hline & Other & 440 & 55 & 45 & & \\
\hline Hispanic & Yes & 460 & 53 & 47 & 2.721 & .099 \\
\hline & No & 2,457 & 49 & 51 & & \\
\hline English Language & Yes & 161 & 57 & 43 & 4.197 & .041 \\
\hline Learner & No & 2,756 & 49 & 51 & & \\
\hline Free \& Reduced & Yes & 2,249 & 46 & 54 & 45.693 & $<.0001$ \\
\hline Meals Program & No & 668 & 61 & 39 & & \\
\hline Special Education & Yes & 798 & 49 & 51 & .013 & .908 \\
\hline & No & 2,119 & 49 & 51 & & \\
\hline Experienced & Yes & 216 & 44 & 56 & 2.637 & .104 \\
\hline Homelessness & No & 2,701 & 50 & 50 & & \\
\hline Experienced Mobility & Yes & 1,647 & 48 & 52 & 2.682 & .102 \\
\hline & No & 1,270 & 51 & 49 & & \\
\hline Worked Year 5 & Yes & 1,541 & 57 & 43 & 69.447 & $<.0001$ \\
\hline & No & 1,376 & 41 & 59 & & \\
\hline Passed HSA - & Yes & 983 & 66 & 34 & 169.990 & $<.0001$ \\
\hline English & No & 1,934 & 41 & 59 & & \\
\hline Passed HSA - Math & Yes & 1,205 & 62 & 38 & 127.231 & $<.0001$ \\
\hline & No & 1,712 & 41 & 59 & & \\
\hline Prior Dropout & Yes & 365 & 33 & 67 & 46.520 & $<.0001$ \\
\hline & No & 2,552 & 52 & 48 & & \\
\hline School Type & & & & & & \\
\hline Traditional School & & 1,942 & 59 & 41 & 218.141 & $<.0001$ \\
\hline Combined School & & 220 & 23 & 77 & & \\
\hline Voc-Tec School & & 169 & 44 & 56 & & \\
\hline Alternative School & & 351 & 32 & 68 & & \\
\hline Charter School & & 235 & 28 & 72 & & \\
\hline & & $\begin{array}{c}\mathrm{M} \\
(\mathrm{SD})\end{array}$ & $\begin{array}{c}\mathrm{M} \\
(\mathrm{SD})\end{array}$ & $\begin{array}{c}\mathrm{M} \\
(\mathrm{SD})\end{array}$ & $t$ & $p$ \\
\hline Weeks Attended ${ }^{\text {a. }}$ & & $\begin{array}{r}25 \\
(10.1) \\
\end{array}$ & $\begin{array}{r}30.3 \\
(5.5) \\
\end{array}$ & $\begin{array}{r}19.8 \\
(10.8) \\
\end{array}$ & -32.66 & $<.0001$ \\
\hline
\end{tabular}

Note. a. $\mathrm{DF}=2929$; Fifth year non-completers may have dropped out or still been enrolled at the end of the fifth year without graduating. 
A summary of school-level characteristics is presented in Table 2. Most schools in the sample were Traditional high schools (73\%), followed by Alternative schools (10\%), Combined schools (7\%), Voc-Tec schools (5\%), and Charter Schools (4\%). On average, the racial composition of schools was about $50 \%$ Black students $(S D=.36)$ and $12 \%$ other race students $(S D=.13)$. The average ethnic composition was $7 \%$ Hispanic students $(S D=.10)$. The average school-level FARMs composition was 55\% $(S D=.27)$. The average school-level percentage of students passing an English HSA was 71\% $(S D=.25)$ and the average passing a math HSA was $74 \%(S D=.25)$.

Table 2.

Descriptive statics for Schools $(\mathrm{k}=216)$

\begin{tabular}{lrr}
\hline & $\mathrm{k}$ & \multicolumn{1}{c}{$\%$} \\
\hline Traditional School & 160 & 73 \\
Combined School & 16 & 7 \\
Voc-Tec School & 11 & 5 \\
Alternative School & 21 & 10 \\
Charter School & 8 & 4 \\
\hline \hline & Mean & $\mathrm{SD}$ \\
\hline \% Female & 50 & .11 \\
\% Black & 48 & .36 \\
\% Other Race & 12 & .13 \\
\% Hispanic & 7 & .10 \\
\% English Language Learner & 2 & .04 \\
\% Free \& Reduced Meals & 55 & .27 \\
\% Special Education & 13 & .09 \\
\% Experienced Homelessness & 4 & .03 \\
\% Experienced Mobility & 32 & .30 \\
\% Worked Year 5 & 67 & .11 \\
\% Passed HSA - English & 71 & .25 \\
\% Passed HSA - Math & 74 & .25 \\
\% Prior Dropout & 7 & .13 \\
Mean weeks attended & 27 & 6.35 \\
\hline
\end{tabular}

\subsection{Measures}


Fifth-year graduation (outcome variable). Fifth-year graduation is a dichotomous variable indicating whether or not a student completed the requirements for a regular Maryland HS Diploma in Year 5 excluding alternative and special education specific credentials $(0=$ No, $1=$ Yes).

Student characteristics. The majority of the student characteristics were coded as dichotomous and were measured in HS. The variables examined included gender $($ male $=0$, female = 1), Hispanic (vs. not), English language learner (ELL; vs. not), Free and Reduced Meals (FARMs) eligible (vs. not), SPED eligible (vs. not), experienced homelessness (vs. did not), and previous dropout (vs. not). School mobility was calculated by assessing whether a student changed schools at least once during the study period (vs. did not). Additionally, we examined variables to indicate academic performance on the English and math (Algebra) high school assessments (HSA), which were the end of course exams needed for graduation in Maryland at the time of this study. The English and math HSA are typically taken in the $9^{\text {th }}$ or $10^{\text {th }}$ grade and can be repeated if the student does not pass on their first attempt. An indicator of passing the math HSA (vs. no pass) and passing the English HSA (vs. no pass) were created describing whether a student had passed each of the tests by the beginning of Year 5. Just over half of the student population that met inclusion criteria for this study was White $(55 \%)$ and just over a third was Black (36\%). The remaining racial groups ranged from less than one to about four percent. Therefore, we created three dummy variables for race (Black, White, Other race). Student attendance was calculated as the number of five-day school week equivalents that students were in attendance during the August-to-June reporting period of the Year 5 school year, ranging from 18 to 36. 
Next, variables were created to assess whether students from the study sample participated in the workforce during Years 5 and 6. Participation in the workforce was calculated by examining quarterly wage records for quarters 3 and 4 in annual years 2013 and 2014 and quarters 1 and 2 for annual year 2014 and 2015 to align with Year 5 and Year 6. A student with wages in any quarter during that school year was coded as participating in the workforce (vs. not). Workforce participation is included for students working for employers in Maryland subject to unemployment insurance, excluding federal government or military employment, selfemployment, and independent contractors. Finally, a dummy variable was created to indicate whether a student enrolled in a Maryland or out-of-state college in Year 6.

School characteristics. A series of dummy variables were created to indicate whether a school was a vocational/technological (Voc-Tec) school (vs. not), Alternative school (vs. not) or a Combined school (e.g. $6^{\text {th }}-12^{\text {th }}$ grades; vs. not). All school types were compared to the reference category Traditional HS. The remaining school-level variables were operationalized by calculating the school-wide concentrations of student characteristics (e.g. percentage of students who worked in Year 5) with the exception of weeks attended, which was operationalized as the average attendance across the student body of a particular school. Students were assigned the school-level values for the institution that the student attended during their final Year 5 enrollment.

\subsection{Data Analyses}

All analyses for the present study were conducted using SAS, Version 9.3. Less than 10 students had missing data on at least one of the variables included in this study. Listwise deletion was used resulting in a final sample of 2,917. Data were not missing at random. Students with missing data were more likely to be fifth-year graduates. 
We used a multilevel generalized linear mixed modeling approach for binary data using the GLIMMIX module for SAS 9.3 to examine the predictors of fifth-year graduation. A logit link was used to accommodate the binary outcome (Dai et al., 2006; reference group=graduation; METHOD=LAPLACE). Between-school differences in the dependent variable were assessed using a varying (random) intercept model. All student- and school-level characteristics were analyzed as constant (fixed) effects (Gelman \& Hill, 2006). We assessed all of the assumptions for the multilevel logistic regression. In order to disentangle group (school-level) effects from level-1 (student-level) effects, we included grand-mean centered school-level equivalents of all student-level parameters, which were group mean centered (Bafumi \& Gelman, 2007; Raudenbush \& Bryk, 2002). Fifth-year graduation outcomes were nested in the student's final school of record in their fifth year. We controlled for the third level of nesting (schools within districts) by entering dummy variables for each of Maryland's 24 jurisdictions (districts) into the model and omitting one at random (Huang, 2016). Finally, descriptive statistics were used to examine Year 6 college enrollment and labor market outcomes for fifth-year graduates and nongraduates.

\section{Results}

First, we looked at the fifth-year graduation rate of returning non-graduates (see Table 3). Overall, half (50\%) of returning non-graduates earned a diploma in Year 5, 15\% dropped out, and just over a third (35\%) were still enrolled at the end of the fifth-year. More than 9 in 10 returning non-graduates were persisters in Year 4. More than half $(51 \%)$ of the persisting students earned a diploma in the fifth-year, 14\% dropped out in Year 5, and about a third (35\%) were still enrolled at the end of the fifth-year. Five percent of returning non-graduates enrolled in their fifth-year after having dropped out in Year 4. A little under a third of students who had 
dropped out in Year 4 (31\%) earned a diploma by the end of Year 5. Nearly two in five (39\%) of the Year 4 dropouts also dropped out in Year 5 and about a third (31\%) were still enrolled at the end of the fifth-year.

Table 3

Fifth-Year Outcomes for Returning Non-graduates $(N=2,793)$

\begin{tabular}{|c|c|c|c|c|}
\hline & Total & Graduated & $\begin{array}{c}\text { Dropped } \\
\text { out }\end{array}$ & $\begin{array}{c}\text { Still } \\
\text { Enrollec }\end{array}$ \\
\hline & $N$ & $\%$ & $\%$ & $\%$ \\
\hline Total & 2,793 & 50 & 15 & 35 \\
\hline Persister (Year 4) & 2,662 & 51 & 14 & 35 \\
\hline Dropout (Year 4) & 131 & 31 & 39 & 31 \\
\hline
\end{tabular}

Note. 124 students in the final study sample were not enrolled during Year 4 and thus had no Year 4 exit data.

\subsection{Multivariate Analyses}

The z-test for the covariance parameters $(z=5.77, p<.0001)$ indicated statistically significant between-school variation in fifth-year graduation outcomes, providing justification for the use of MLM techniques (Hox, 2002). Results for the multilevel model fitted to evaluate the contributions of student and school-level factors on earning a diploma in the fifth-year of HS are presented in Table 4. 
Table 4

Summary of Results for the Multilevel logit Model Fitted to Evaluate the Contributions of Student and School-level Factors on Earning a Diploma in the Fifth-year of High School $(N=2,917)$

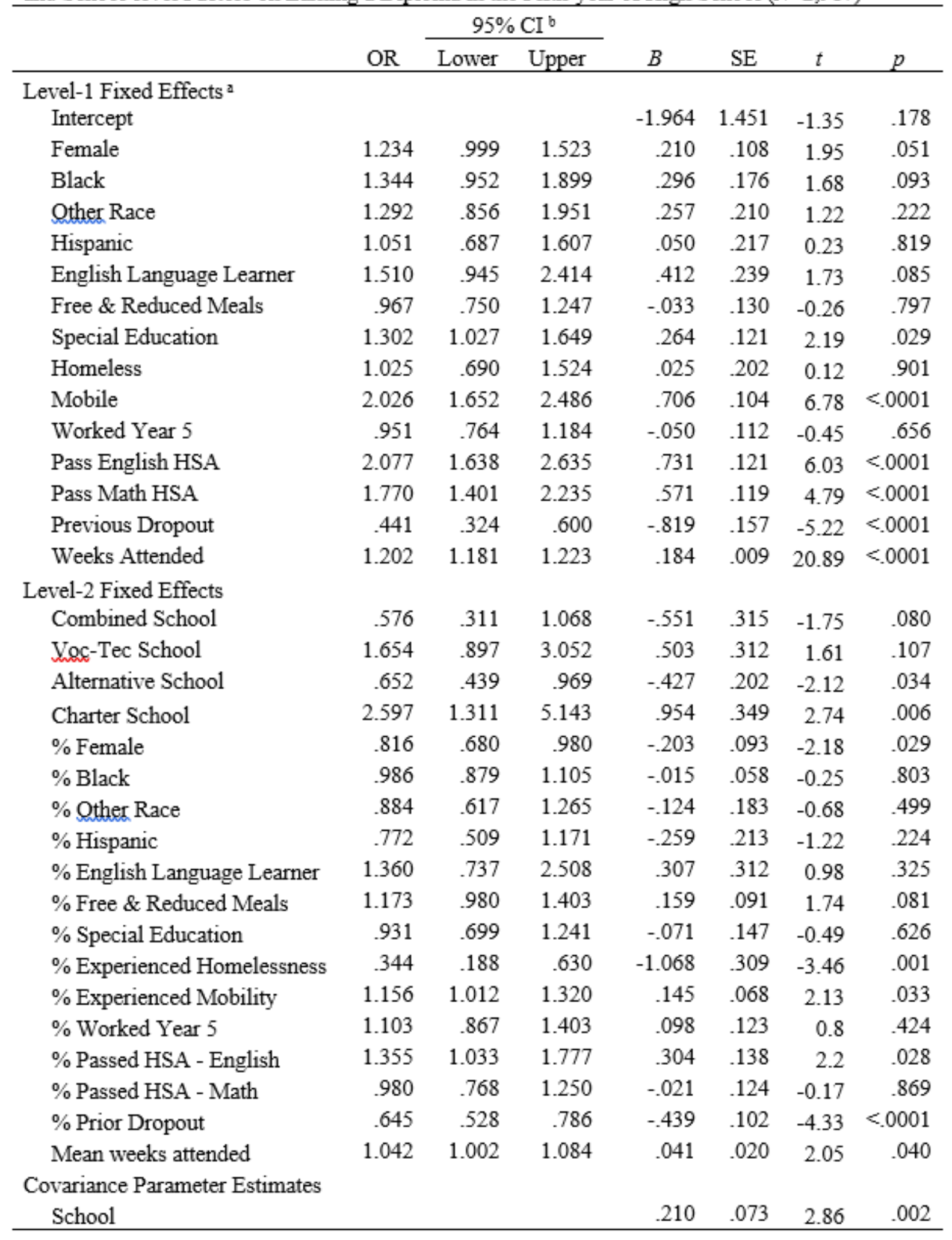

Note. Dummy variables for school districts were included in the model to account for the between-district variance in the dependent variable. Estimates for these parameters are not reported a. The reference category is 1.00: Fifth-year Graduate. b. Confidence Interval for the Odds Ratio. HSA = high school assessment. 


\subsection{Student-level factors}

Student who were eligible for special education services were more likely to earn a diploma in their fifth-year of HS when compared to their non-eligible peers $(O R=1.302, p<.029)$ Students who changed schools during high school $(O R=2.026, p<.0001)$ and students who had passed their English $(O R=2.077, p<.0001)$ or Math HSA $(O R=1.770, p<.0001)$ before Year 5 were more likely to earn a diploma in the fifth-year. Students who temporarily dropped out during the first four years of HS were less likely to earn a diploma in Year $5(O R=.441$, $p<.0001)$. Each additional week of HS attended $(O R=1.202, p<.0001)$ in Year 5 was associated with greater likelihood of fifth-year graduation. After controlling for other variables in the model, there was no significant relationship between being Female $(p=.051)$, Black $(p=.093)$, Other race $(p=.222)$, Hispanic $(p=.819)$, an English language learner $(p=.085)$, FARMs eligible $(p=.797)$, experiencing homelessness $(p=.901)$ or working during Year $5(p=.656)$ and graduating in the fifth year.

\subsection{School-level factors}

Students who attended an Alternative HS $(O R=.652, p=.034)$ were less likely to earn a diploma in Year 5 compared to students attending a Traditional HS. Students who attended a Charter school $(O R=2.597, p=.006)$ were more likely to earn a diploma in Year 5 compared to students attending a traditional HS. There was no significant relationship between attending a Combined HS ( $p=.080)$ or a Voc-Tec school $(p=.107)$ and earning a diploma in the fifth-year.

Students who attended schools with higher concentrations of female students $(O R=0.816$, $p=.029)$ and with higher concentrations of students with of students who experienced homelessness $(O R=.344, p=.001)$ were less likely to graduate in the fifth year. Students who attended schools with higher concentrations of students who had changed schools during high school $(O R=1.042, p=.040)$ were more likely to earn a diploma in the fifth year. Students who 
attended a school where a higher percentage of students had passed their English HSA $(O R=1.355, p=.028)$ were more likely to graduate in the fifth year. Students who attended a school with higher concentrations students with prior dropouts $(O R=.645, p<.0001)$ were less likely to earn a diploma in Year 5. Students who attended a school with higher average levels of attendance were more likely to earn a diploma in Year $5(O R=1.042, p=.040)$. After controlling for other variables in the model, there was no significant relationship between school-level concentrations of Black students $(p=.803)$, Other Race students $(p=.499)$, Hispanic students $(p=.224)$, English language learners ( $p=.325)$, FARMs eligible students $(p=.081)$, students eligible for special educations $(p=.626)$, or working students $(p=.424)$, and earning a diploma in the fifth year.

Table 5 includes a descriptive analysis comparing the sixth year academic and early labor market outcomes for students who graduated in the fifth-year to students who did not graduate in the fifth-year. More than half (54\%) of the fifth-year graduates and non-graduates (52\%) worked more than three fiscal quarters in Year 6 but did not attend college. Five percent of fifth-year graduates enrolled in college in Year 6, but did not work, compared to $1 \%$ of non-graduates. All of the students who did enroll in college enrolled in two-year colleges. Thirteen percent of fifthyear graduates enrolled in college and worked in Year 6, compared to $2 \%$ of non-graduates. Nearly one third of fifth-year graduates (29\%) had no record of employment or college enrollment in Year 6 compared to nearly half of non-graduates (45\%). 
Table 5

Sixth Year Labor Experience and College Enrollment for Fifth Year Graduates and Non-Graduates

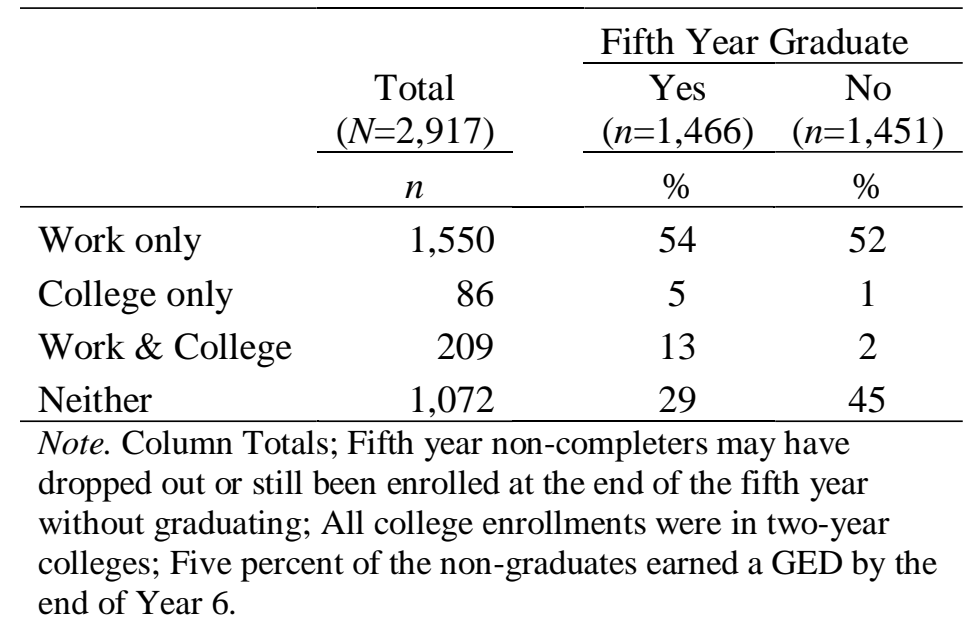

\section{Discussion}

The current study used linked administrative data to examine the near-term academic and workforce outcomes of persisting non-graduates in Maryland public schools. In the present study we provide additional empirical evidence for the existence of a large subgroup of non-graduates who persist into a fifth-year of high school. This is consistent with three prior studies that examined the rates of persisting and dropping out in districtwide (Hill \& Mirakhur, 2018; Uretsky, 2019) and statewide data (Uretsky, Henneberger, \& Woolley, 2016). We use an ecological systems framework (Bronfenbrenner, 2005) to broaden the understanding of the student- and school-level characteristics that are associated with fifth-year graduation. Consistent with prior theory on HS student performance (Rumberger, 2011), we find that student engagement and achievement, as well as school structure and composition were associated with fifth-year graduation. Of the students who enrolled in a fifth-year of HS, just over half earned a diploma by the year's end, and a third were still enrolled despite not earning a diploma. 
Additionally, we show that fifth-year graduates had better outcomes in the sixth year, including higher rates of college and workforce participation.

\subsection{Student-level characteristics}

Students eligible for special education services were more likely to graduate in Year 5 compared to students who were not. This is discrepant with prior research describing lower rates of four-year graduation and higher rates of dropout for such students (Rumberger \& Lim, 2008). However, Zablocki and Krezmien (2013) reported no significant effects on four-year graduation for special education after controlling for student academic experience, including grade retention, suspension, grades, and emotional engagement. It is reasonable to expect that special education students who are seeking a regular HS diploma may require additional time to fulfil diploma requirements. Prior research has indicated that supportive non-parental adults can serve as mentors and help to build assets for students (Rhodes \& Roffman, 2003). Students receiving special education services are provided additional adult supports and individualized services through the public-school system, which may help to set the students up for success in a fifth year. Finally, a sorting effect may be at play, so that the students receiving special education services who enroll in Year 5 are essentially different from students who left school earlier or graduated on-time. Our study excludes students who received a certificate of completion, a common outcome for students receiving special education services. As such, it is possible that many of the lower achieving students were excluded from the study, and many of the highest achieving students receiving special education services sought to earn a regular high school diploma but needed a fifth year to meet those requirements.

Consistent with the literature on student attendance and dropout in the first four years of HS (Archambault, Janosz, Fallu, \& Pagani, 2009; Berliner et al., 2008; Bowers et al., 2013; Carl 
et al., 2013; Mac Iver \& Messel, 2012), students who attended additional weeks of school in the fifth-year and students who had not previously dropped out of school were more likely to graduate in the fifth-year. Additionally, consistent with prior research linking student academic achievement and HS graduation (Bower et al., 2013; Rumberger, 2011), students who passed an English or math HSA by the end of Year 4 were more likely to graduate in the fifth-year. Our findings are the first to extend the association between academic engagement and achievement and HS graduation into the fifth year of HS. Our findings indicate that academic engagement and achievement as measured by attendance and standardized test scores may be good indicators of graduation, even after the typical four years of HS attendance.

Surprisingly, experiencing school mobility (i.e., changing schools at least once during high school) was related to increased likelihood of graduating from high school in the fifth year. Recent research links student mobility to negative educational outcomes, including delays in academic progress and disruptions in social adjustment for students at all grade levels (Benenson et al., 2011; Dupere et al., 2015; Fantuzzo et al., 2012). This research largely stems from the perspective that mobility is caused by negative life circumstances, such as divorce, trauma, homelessness, and poverty. However, families and students may also intentionally switch schools in order to get a fresh start at a new school, where they may perceive it to be easier to graduate. For example, evidence from the Moving to Opportunity Study shows that vulnerable families that change school, tend to move into equally or less rigorous schools (de Souza Briggs, Ferryman, Popkin, \& Rendon, 2008). Such moves have been found to lead to improved likelihood of graduation (Swanson \& Schneider, 1999). "A different school may provide a new learning environment that conforms more closely to a family's educational values and expectations or better accommodates the academic needs of a specific student" (Swanson \& 
Schneider, 1999, p. 56). This may be especially critical for the population of students who are persisting into the fifth year. Furthermore, HS graduation is determined by a combination of objective standardized test scores and more subjective factors that vary from school to school, such as course rigor and teachers' grading policies.

\subsection{School-level characteristics}

School structure. Consistent with theoretical and empirical evidence linking school structure to fourth year graduation (Rumberger \& Lim, 2008), we found a significant association between school structure and fifth-year graduation. About two thirds of fifth year students were enrolled in Traditional high schools. Just over $10 \%$ of students were enrolled in an Alternative school and just under $10 \%$ were enrolled in a Charter school in their fifth year. Students who attended alternative schools were less likely to graduate in the fifth-year, when compared to students who attended a traditional HS. In Maryland public schools, alternative schools serve students who are not succeeding in regular public schools, including students who have been repeatedly disciplined in traditional HSs, have unique needs (e.g., pregnant students; students involved in the juvenile justice system), or who have otherwise fallen behind in credit accumulation. By design, the students served by alternative schools are a unique population of students, already less likely to graduate from HS, which may contribute to lower likelihood of graduating into the fifth year. Additionally, Alternative schools may expend more resources serving the daily needs of the unique population of students, providing fewer resources to focus on graduation specifically. Students who attended Charter schools were more likely to graduate in the fifth year, when compared to students who attended a Traditional HS. Prior research on charter schools reports mixed results on their effectiveness for student achievement (Berends, Watral, Teasley, \& Nicotera, 2006; Zimmer, Gill, Booker, Lavertu, \& Sass, 2009). In Maryland, 
charter schools are part of the public-school system. Families and students in the fifth year may seek out Charter schools due to their unique structural aspects (e.g., small class size; small school size; individualized instruction; adaptive education), which may cater to the particular population of students who are enrolled in a fifth year of high school.

School composition. Again, consistent with theoretical and empirical evidence on fouryear graduation (Rumberger \& Lim, 2008; Rumberger \& Thomas, 2000; Rumberger \& Palardy, 2005; Saunders et al., 2008; Subedi \& Howard, 2013), we found a significant association between measures of school composition and fifth-year graduation. Consistent with research examining disparities in academic achievement, we found two significant demographic compositional effects. Students attending schools with higher percentages of female students and higher percentages of homeless students were less likely to graduate in the fifth year. Discrepant with prior research, we found no significant relationship between school-level race/ethnicity or poverty and fifth-year graduation, after controlling for other variables in the model. Prior research reports significant negative relations between minority (Sander, 2001) and income composition (Henneberger et al., 2020; Rumberger \& Thomas, 2000) and subsequent academic outcomes, including high school graduation, dropout, and school turnover. In studies examining school composition, demographic factors may be functioning as proxies for wide ranging inequities, including inequitable access to quality public education and differences in family background (De Witte et al., 2013; Rumberger \& Lim, 2008).

Several school compositional factors related to academic engagement and achievement were significantly associated with fifth-year graduation, which is consistent with the literature on fourth year graduation (Rumberger \& Thomas, 2000; Subedi \& Howard, 2013). Students attending schools with higher attendance rates, higher percentages of students who passed the 
English HSA, and lower percentages of students who had previously dropped out of HS were more likely to graduate in the fifth year. Surprisingly, students attending schools with more students who had experienced school mobility were more likely to graduate in the fifth year, although this association was not as strong as the association at the student-level. Schools with highly mobile populations may have more options for modified graduation requirements, which may attract struggling students. Additionally, these schools may be more likely to have supportive services and policies, such as credit recovery programming, tutoring, or childcare. Our results suggest that targeting prevention and intervention toward schools based on engagement and achievement compositional factors may be more beneficial in promoting fifthyear graduation than targeting schools based on demographic compositional factors.

\subsection{College and workforce outcomes}

The current paper is the first known study to examine the college and workforce outcomes of persisting non-graduates. We found that persisting students who earned a diploma in the fifth-year had more favorable college and workforce outcomes in the sixth year compared to nongraduates. This finding is consistent with prior research indicating that earning a HS diploma is associated with important life outcomes such as physical health, mental well-being, employment, and higher wages (Blackwell et al., 2014; Rouse, 2007). Nearly half of fifth year nongraduates were neither engaged in school or the workforce in the sixth year, which means that they were not earning any measured human or economic capital. This disengagement represents a significant social and economic opportunity loss for society (Belfield et al., 2012). Additionally, youth not engaged with either school or the workforce are more likely to be involved in the criminal justice system and rely on social support and welfare programs (Belfield et al., 2012). 


\section{Strengths and Limitations}

The current study has a number of methodological strengths. First, we used statewide population-level data from Maryland public schools, which provided us with the ability to observe subgroups of students that are often too small to examine in research samples. For example, compared to the population of graduates, the number of non-graduates is relatively small, and subgroup sizes within that group (e.g. persisters, dropouts) are even smaller. Second, we used multilevel modeling to disaggregate the role of student and school characteristics on graduation in the fifth-year, which provided us with the ability to separate and explain studentlevel variation and school-level variation in the outcome, providing meaningful research and practice implications at each level. Third, the linked longitudinal nature of the data provided us with the ability to examine the college and career outcomes for nongraduates, which have not been widely studied to-date. Better understanding outcomes after HS is a key component of developing targeted prevention and intervention for HS students.

The findings of this study should be interpreted within the context of the following limitations. First, the population-level data were from one state— Maryland — and therefore, would only be generalizable to populations with similar student and school demographics. Second, unmeasured confounders may contribute to results to the degree that the unmeasured variables are correlated with our predictors of interest and fifth-year graduation. For example, Rumberger's (2011) conceptual model also highlighted the importance of family and community factors for high school graduation. These measures were not available for the current study. An additional important unmeasured confounder in our study was exclusionary disciplinary records, including suspensions, which have been associated with graduation in prior research (Zablocki \& Krezmien, 2013). To the degree that unmeasured confounders exist, our results would be 
interpreted as overestimates of the true relationship between predictors and fifth-year graduation. Third, the workforce data included in this study does not include data for federal employment, military employment, self-employment, or private contracting. If nongraduates are more likely to work in these employment sectors, our results would be an underestimate of the percentage of nongraduates participating in the workforce. In addition, people in Maryland may be working in surrounding states, which may bias the results to the degree that students in different subgroups (e.g., 5th year graduates, non-graduates) differentially work for out of state employers. One proxy for the percentage of students who work out of state may be the percentage of students who attend college out of state. In prior analyses, we found that similar percentages of students across subgroups attend college out of state, which adds to the confidence in our results (MLDS Center, n.d.). Finally, attendance was reported in blocks by enrollment period (e.g. total days attended). This prevented us from observing and distinguishing between daily patterns of attendance.

\subsection{Implications for research}

The use of a multilevel modeling approach in the current study enabled us to look at the effects of school-level variables above and beyond the effects of the individual student characteristics of interest. Consistent with Bronfenbrenner's (2005) ecological systems theory, we found several student- and school-level characteristics that were associated with fifth-year graduation. It will be important for future research to consider how student- and school-level characteristics interact to produce educational outcomes. For example, it is possible that subgroups of fifth-year students may differentially benefit from attending schools with particular characteristics. Additionally, the current study controlled for local school system, Maryland's equivalent to school district, and future research could benefit from using multilevel modeling to 
examine the district-level characteristics (e.g., districtwide policy, programming, or curriculum) that may lead to positive outcomes in the fifth year. Future research should also examine the factors and conditions that promote or inhibit student enrollment in a fifth year of HS.

In the current study, we examined fifth and sixth year academic and workforce outcomes for a statewide cohort of persisting non-graduates. Future research would benefit from examining longer-term outcomes of persisters and returning dropouts, including comparisons of persistence in college and the workforce, college degree attainment, and workforce earnings for fifth-year graduates and nongraduates. Additional comparisons to alternate degree holders (e.g. GED) may also be fruitful to understand how outcomes differ for students who spend an extra year in HS to earn a diploma when compared to students who earn an alternative credential. Replication research focusing on national samples or cohort data from other states would provide information on whether the population of persisting students, and the relationships identified in Maryland, are unique or whether these findings are generalizable to other locations.

Several important variables that were not measured in the current study should be included in future studies to further refine the understanding of fifth-year graduation. Exclusionary discipline practices, including suspensions, and juvenile justice records may provide some insight into key differences between the early experiences of high school dropouts and persisters. Additionally, family (e.g., family income; parental educational status) and community (e.g., access to supports such as Boys and Girls Clubs) factors may be important for further understanding both educational persistence and fifth-year graduation. A comprehensive study examining student, school, family, and community factors would be consistent with prior theoretical models (Bronfenbrenner, 2005; Rumberger, 2011) and would provide an 
understanding of the relative importance of factors across multiple levels of the ecological system, further refining prevention and intervention targets.

Finally, qualitative research methods, including interviews and focus groups, may help to identify some of the underlying mechanisms that lead to more positive graduation outcomes for students with characteristics that have been historically associated with less favorable academic outcomes (e.g. special education, mobile students). For example, motivational resilience (Skinner, 2016) may be underpinning the persistence of some, whereas economic factors may be underpinning the persistence of other students. Better understanding the underlying mechanisms associated with more positive outcomes can help to develop and refine prevention and intervention programs aimed at improving high school graduation rates for vulnerable student groups.

\subsection{Implications for Practice}

Our findings have a number of key implications for practice. First, school officials should use early warning indicators to identify students who may be likely to dropout as early as possible in the student's high school career (Dynarski et al., 2008). Second, school officials should use evidence-based practices, such as assigned adult supports, academic enrichment and supports, personalized instruction, and programs that help improve behavioral and social skills (Dynarksi et al., 2008). Persisters remain behaviorally engaged in school, and as such, persisting students are easier to locate and engage with evidence-based practices, than dropouts who, by definition, have formally disengaged from the school. Third, there may be some measurable motivational factors that can be leveraged to promote HS graduation among this vulnerable and understudied population. For example, making the curriculum relevant to post-high school career options has been shown to improve motivation and engagement for vulnerable students 
(Dynarski et al., 2008). Students in the current study who persisted to obtain a HS degree ultimately had better life outcomes, including more favorable college and career outcomes, underscoring the importance of encouraging re-enrollment and persistence.

Additionally, school officials should be cognizant of how current practices work to deconstruct or reinforce existing outcome disparities. Student groups that are often described as vulnerable (e.g. Black, ELL, Hispanic students) were not less likely to graduate in the fifth year. Special education and mobile students actually had increased odds of earning a diploma in the fifth year, outperforming their counterparts after controlling for other factors. As suggested by De Witte et al. (2013), racial, ethnic, and disability disparities found in prior studies may actually be artifacts of other ongoing inequities (e.g., historic poverty and oppression). This finding is important to consider in context of the lower four-year graduation rates for those same students (Rumberger and Lim 2008; De Witte et al., 2013). Previous research did not find special education participation to affect a student's odds of persisting versus on-time graduation after controlling for academic and social factors (Uretsky, 2019). That research, however, examined fourth year outcomes in a single urban district, while the current study is focused on fifth-year outcomes using a statewide sample, which may explain the differing results (Uretsky, 2019). Still, it is worth considering that the motivational underpinnings of persisting beyond the fourth year may differ based on special education status. If true, the targets for intervention would also need to differ to ensure that all subgroups of students would benefit (Eccles, et al. 1993). The evidence-based practices and policies necessary to move persisting students toward graduation are likely not the same for all students, indicating a need for personalized prevention and intervention (Dynarski et al., 2008). 
Lastly, there were multiple indicators at the student- and school-levels that may be useful in identifying which non-graduates are unlikely to earn a diploma in Year 5. Our findings indicate that academic engagement and achievement as measured by prior dropout, attendance, and standardized test scores may be good indicators of graduation, even after the typical four years of HS attendance. These findings are similar to those on four-year graduation and these factors are often included in early warning systems (Bowers et al., 2013; Dynarski et al., 2008). Additionally, alternative schools and schools with higher percentages of prior dropout and homelessness may be unique for targeting interventions that can help students in the fifth year. Our results suggest that school-level interventions focused on completion of the fifth year might be better targeted using different factors than those typically associated with prevention and intervention in the fourth-year. For example, low-income and minority schools are often targeted for prevention and intervention, but our results suggest that, after controlling for other factors, school-level engagement and achievement may be the most important compositional factors to consider when targeting schools for prevention and intervention to promote graduation in the fifth year. Prevention and intervention that is targeted at both the student and school levels seems most appropriate for improving outcomes and targeting at both levels opens the door to delivering deliberate and well-timed intervention to promote HS graduation among this vulnerable, but engaged student group.

\section{Conclusion}

Students who do not earn a HS diploma in four years are not a homogenous group, and similarly their academic and workforce outcomes are diverse. As such, any efforts to promote positive achievements after the traditional four years of HS have elapsed would benefit from a nuanced conceptualization of the phenomenon. It is also important to consider the broader social 
forces that disproportionately affect young people as they are beginning their transition into adulthood. In general, youth from marginalized communities that are beset by the institutional and interpersonal repercussions of racism, heterosexism, and poverty are more likely to dropout and less likely to earn a high school diploma (De Witte et al., 2013). The lack of research examining the ensuing academic and workforce trajectories of four-year non-graduates likely perpetuates the same broad social injustices that have been well documented by dropout scholars. The development and effective delivery of interventions that focus on the mechanisms underpinning persisting may help to improve long-term student academic and workforce outcomes for vulnerable students at a critical juncture in their journey towards adulthood. 


\section{References}

Altman, D. G., Schulz, K. F., Moher, D., Egger, M., Davidoff, F., Elbourne, D., ... \& Lang, T. (2001). The revised CONSORT statement for reporting randomized trials: explanation and elaboration. Annals of internal medicine, 134(8), 663-694.

Allensworth, E. M., \& Easton, J. Q. (2007). What matters for staying on track and graduating in Chicago public high schools? (Research Report July 2007). Retrieved from Consortium on Chicago School Research website: http://ccsr.uchicago.edu/publications/what-mattersstaying-track-and-graduating-chicago-public-schools

Archambault, I., Janosz, M., Fallu, J.-S., \& Pagani, L. S. (2009). Student engagement and its relationship with early high school dropout. Journal of Adolescence, 32(3), 651-670. http://doi.org/10.1016/j.adolescence.2008.06.007

Bafumi, J., \& Gelman, A. (2007). Fitting Multilevel Models When Predictors and Group Effects Correlate. SSRN Electronic Journal. https://doi.org/10.2139/ssrn.1010095

Belfield, C. R., Levin, H. M., \& Rosen, R. (2012). The Economic Value of Opportunity Youth. Corporation for National and Community Service. Paper in association with Civic Enterprises for the Corporation for National and Community Service. Retrieved from http://www.civicenterprises.net/MediaLibrary/Docs/econ_value_opportunity_youth.pdf

Benenson, J. F., Markovits, H., Thompson, M. E., \& Wrangham, R. W. (2011). Under threat of social exclusion, females exclude more than males. Psychological Science, 22(4), 538544. http://doi.org/10.1177/0956797611402511 
Berends, M., Watral, C., Teasley, B., \& Nicotera, A. (2006). Charter school effects on achievement: Where we are and where we're going. Nashville, TN: National Center on School Choice.

Berliner, B., Barrat, V. X., Fong, A. B., \& Shirk, P. B. (2008). Reenrollment of high school dropouts in a large, urban school district. Issues \& answers. (Research Report No. 056). Retrieved from the National Center for Educational Evaluation and Regional Assistance website: http://ies.ed.gov/ncee/edlabs/regions/west/pdf/REL_2008056.pdf

Blackwell, D. L., Lucas, J. W., Clarke, T. C. (2014) Summary health statistics for U.S. adults: National Health Interview Survey, 2012. (Vital Health Stat 10 Report no. 260). Downloaded from the National Center for Health Statistics website: http://www.cdc.gov/nchs/data/series/sr_10/sr10_260.pdf

Booker, K., Sass, T. R., Gill, B., \& Zimmer, R. (2011). The effects of charter high schools on educational attainment. Journal of Labor Economics, 29(2), 377-415.

Bowers, A. J. (2010). Grades and graduation: A longitudinal risk perspective to identify student dropouts. The Journal of Educational Research, 103(3), 191-207. http://doi.org/10.1080/00220670903382970

Bowers, A. J., Sprott, R., \& Taff, S. A. (2013). Do we know who will drop out?: A review of the predictors of dropping out of high school: Precision, sensitivity, and specificity. The High School Journal, 96(2), 77-100. DOI: 10.1353/hsj.2013.0000

Bronfenbrenner, U. (2005). Making human beings human: Bioecological perspectives on human development. Thousand Oaks: Sage Publications. 
Carl, B., Richardson, J. T., Cheng, E., Kim, H., \& Meyer, R. H. (2013). Theory and application of early warning systems for high school and beyond. Journal of Education for Students Placed at Risk (JESPAR), 18(1), 29-49. http://doi.org/10.1080/10824669.2013.745374

Dai, J., Li, Z., \& Rocke, D. (2006). Hierarchical logistic regression modeling with SAS GLIMMIX. In Proceedings of the thirty-first annual SAS users group international conference. Cary, North Carolina: SAS Institute Inc.

de Souza Briggs, X., Ferryman, K. S., Popkin, S. J., \& Rendon, M. (2008). Why did the moving to opportunity experiment not get young people into better schools?. Housing Policy Debate, 19(1), 53-91.

De Witte, K., Cabus, S., Thyssen, G., Groot, W., \& van den Brink, H. M. (2013). A critical review of the literature on school dropout. Educational Research Review, 10, 13-28. https://doi.org/10.1016/j.edurev.2013.05.002

Dupere, V., Archambault, I., Leventhal, T., Dion, E., \& Anderson, S. (2015). School mobility and school-age children's social adjustment. Developmental Psychology, 51(2), 197-210. http://doi.org/10.1037/a0038480

Dynarski, M., Clarke, L., Cobb, B., Finn, J., Rumberger, R., and Smink, J. (2008). Dropout Prevention: A Practice Guide (NCEE 2008-4025). Washington, DC: National Center for Education Evaluation and Regional Assistance, Institute of Education Sciences, U.S. Department of Education. Retrieved from http://ies.ed.gov/ncee/wwc.

Fantuzzo, J. W., LeBoeuf, W. A., Chen, C.C., Rouse, H. L., \& Culhane, D. P. (2012). The unique and combined effects of homelessness and school mobility on the educational 
outcomes of young children. Educational Researcher, 41(9), 393-402. http://doi.org/10.3102/0013189X12468210

Freeman, J., \& Simonsen, B. (2015). Examining the Impact of Policy and Practice Interventions on High School Dropout and School Completion Rates: A Systematic Review of the Literature. Review of Educational Research, 85(2), 205-248. https://doi.org/10.3102/0034654314554431

Freudenberg, N., and Ruglis, J. 2007. "Peer reviewed: Reframing school dropout as a public health issue." Preventing Chronic Disease, 4(4): 1-11.

Gelman, A., \& Hill, J. (2006). Data Analysis Using Regression and Multilevel/Hierarchical Models. Cambridge University Press.

Henneberger, A.K., Rose, B.A., Mushonga, D.R., Nam, B., \& Preston, A.M. (2020).

Concentrated poverty and long-term academic and early labor market outcomes. Manuscript submitted for publication.

Hill, K., \& Mirakhur, Z. (2018). Exploring the Pathways and Outcomes of Students Who Don't Graduate in Four Years, But Remain Enrolled in NYC High Schools (p. 28). The Research Alliance of New York City. Retrieved from https://research.steinhardt.nyu.edu/research_alliance/publications/persisting_students

Hox, J. (2002). Multi-Level Analysis. London: Lawrence Erlbaum Associates, Publishers. Huang, F. L. (2016). Alternatives to multilevel modeling for the analysis of clustered data. The Journal of Experimental Education, 84(1), 175-196. doi:0.1080/00220973.2014.952397 
Kena, G., Musu-Gillette, L., Robinson, J., Wang, X., Rathbun, A., Zhang, J., \& WilkinsonFlicker, S. (2014). The Condition of Education 2015 (NCES Publication number 2015144). Retrieved from National Center for Education Statistics website: http://nces.ed.gov/pubs2015/2015144.pdf

Mac Iver, M. A., \& Messel, M. (2012). Predicting high school outcomes in the Baltimore city public schools. (Senior Education Fellow Research Report No. 7). Retrieved from Council of the Great City Schools website: http://cgcs.org/cms/lib/DC00001581/Centricity/Domain/85/CGCS_2012-0817_SUERFv7.pdf

Maryland Longitudinal Data System Center. (n.d.). [College enrollment]. Unpublished raw data.

Maryland State Department of Education (2020) Maryland Report Card 2019 Progress Report State and School Systems. Retrieved from https://reportcard.msde.maryland.gov/

Maynard, B. R., Salas-Wright, C. P., \& Vaughn, M. G. (2015). High school dropouts in emerging adulthood: Substance use, mental health problems, and crime. Community Mental Health Journal, 51(3), 289-299. http://doi.org/10.1007/s10597-014-9760-5

Moher, D., Schulz, K. F., \& Altman, D. (2001). The CONSORT statement: revised recommendations for improving the quality of reports of parallel-group randomized trials. JAMA, 285(15), 1987-1991. 
National Center for Education Statistics [NCES] (2010) Statistical methods for protecting personally identifiable information in aggregate reporting. (SLDS Technical Brief No. 3, NCES 2011-603). Retrieved from https://nces.ed.gov/pubsearch/pubsinfo.asp?pubid=2011603

Pallas, A. M. (2003). Educational transitions, trajectories, and pathways. In J. T. Mortimer \& M. J. Shanahan (Eds.), Handbook of the Life Course (pp. 165-184). New York: Kluwer Academic/Plenum Publishers.

Raudenbush, S. W., \& Bryk, A. S. (2002). Hierarchical linear models: Applications and data analysis methods (Vol. 1). sage.

Rhodes, J. E., \& Roffman, J. G. (2003). Nonparental adults as asset builders in the lives of youth. In Developmental assets and asset-building communities (pp. 195-209). Springer, Boston, MA.

Rouse, C. E. (2007). Quantifying the Costs of Inadequate Education: Consequences of the Labor Market. In C.R. Belfield and H.M. Levin (Eds.), The Price We Pay: Economic and Social Consequences of Inadequate Education (pp. 99-124). Washington, DC: Brookings Institution Press.

Rumberger, R. W. \& Sublett, C. (2017). Accounting for delayed high school graduates in California (Research Report No. 22). Retrieved from the California Dropout Research Project website: https://cdrpsb.org/download.php?file=researchreport22.pdf 
Rumberger, R. W. (2011). Dropping out: Why students drop out of high school and what can be done about it. Cambridge, MA: Harvard University Press.

Rumberger, R. W., \& Lim, S. A. (2008). Why students drop out of school: A review of 25 years of research. (Research Report No. 15). Retrieved from Dropout Research Project website: $\underline{\text { http://cdrp.ucsb.edu/dropouts/pubs_reports.htm. }}$.

Rumberger, R. W., \& Palardy, G. J. (2004). Multilevel models for school effectiveness research. In D. Kaplan (Ed.) The SAGE handbook of quantitative methodology for the social sciences (pp 236-259). doi:10.4135/9781412986311.n13

Rumberger, R. W., \& Thomas, S. L. (2000). The distribution of dropout and turnover rates among urban and suburban high schools. Sociology of Education, 73(1), 39. http://doi.org/10.2307/2673198

Sander, W. (2001). Chicago public schools and student achievement. Urban Education, 36(1), 27-38. doi:10.1177/0042085901361003

Saunders, M., Silver, D., Zarate, E., \& Team, L. S. (2008). The Impact of High Schools on Student Achievement within the Los Angeles Unified School District.

Skinner, E. A. 2016. Engagement and disaffection as central to processes of motivational resilience and development. In Handbook of Motivation at School, (Eds.) Wentzel, K., \& Miele, D. New York: Routledge Press (pp 145-164). 
Subedi, B. R., \& Howard, M. (2013). Predicting high school graduation and dropout for at-risk students: A multilevel approach to measure school effectiveness. Advances in Education, 2(1), 11-17.

Swanson, C. B., \& Schneider, B. (1999). Students on the move: Residential and educational mobility in America's schools. Sociology of Education, 72, 54-67.

Uretsky, M. C. (2019). High school completion in context: Student- and school-level factors related to on-time graduation and persisting. Teachers College Record.

Uretsky, M. C., Henneberger, A.K., \& Woolley, M.E. (2016) High school persisters: An examination of college and workforce outcomes. Maryland Longitudinal Data System Center: Baltimore, MD. Retrieved from https://mldscenter.maryland.gov/ResearchReports.html

Zablocki, M., \& Krezmien, M. P. (2013). Drop-out predictors among students with highincidence disabilities a national longitudinal and transitional study 2 analysis. Journal of Disability Policy Studies, 24, 53-64. http://dx.doi.org/10.1177/1044207311427726

Zaff, J. F., Donlan, A., Gunning, A., Anderson, S. E., McDermott, E., \& Sedaca, M. (2016). Factors that promote high school graduation: A review of the literature. Educational Psychology Review. http://doi.org/10.1007/s10648-016-9363-5

Zimmer, R., Gill, B., Booker, K., Lavertu, S., \& Sass, T. R. (2009). Charter schools in eight states: Effects on achievement, attainment, integration, and competition. Rand Corporation. 